\title{
Precision Medicine Approaches to Prevent Gastric Cancer
}

\author{
Juntaro Matsuzaki ${ }^{1}$, Hitoshi Tsugawa ${ }^{2}$, and Hidekazu Suzuki ${ }^{3}$ \\ ${ }^{1}$ Division of Gastroenterology and Hepatology, Department of Internal Medicine, ${ }^{2}$ Department of Biochemistry, Keio University School \\ of Medicine, Tokyo, and ${ }^{3}$ Department of Gastroenterology and Hepatology, Tokai University School of Medicine, Isehara, Japan
}

\section{Article Info}

Received July 22, 2019

Revised October 18, 2019

Accepted November 15, 2019

Published online January 6, 2020

\section{Corresponding Author}

Hidekazu Suzuki

ORCID https://orcid.org/0000-0002-8994-6163

E-mail hsuzuki@tokai.ac.jp

\begin{abstract}
Gastric cancer remains one of the most common causes of cancer-related death worldwide, although the incidence is declining gradually. The primary risk factor for gastric cancer is Helicobacter pylori infection. The Kyoto global consensus report recommends eradication of $H$. pylori in all infected patients. However, because it is difficult to stratify the risk of carcinogenesis among patients with a history of $H$. pylori infection, annual endoscopic surveillance is performed for everyone after eradication. This review summarizes the current approaches used to screen for novel molecules that could assist in the diagnosis of gastric cancer and reduce mortality. Most well-studied molecules are tissue protein biomarkers expressed by the gastric epithelium and associated with metaplasia-dysplasia-carcinoma sequences. Other strategies focus on the origin of cancer stem cell-related markers, such as CD44, and immune reaction-related markers, such as matrix metallopeptidases. Noninvasive methods such as blood-based approaches are more attractive. Serum pepsinogen levels predict the severity of gastric mucosal atrophy before $H$. pylori eradication, whereas plasma ghrelin levels are associated with atrophy even after eradication. Cell-free DNAs and RNAs are attractive tools for the early detection of cancer. These ideas could lead to the development of more personalized strategies for cancer prevention based on cuttingedge technologies. (Gut Liver 2021;15:3-12)
\end{abstract}

Key Words: Stomach neoplasms; Ghrelin; CD44v9; Microbiota; MicroRNA

\section{INTRODUCTION}

Worldwide, gastric cancer is the fifth most common malignancy and the fourth leading cause of cancer-related death. ${ }^{1}$ More than half of the world's total incident gastric cancers occur in East Asia. Although many factors contribute to the risk of gastric cancer, the single greatest risk factor for the development of non-cardia gastric cancer is infection with Helicobacter pylori (relative risk of 5.9). ${ }^{2}$ Screening strategies for the detection of gastric cancer at an early and more curable stage have led to a significant reduction in mortality from the disease. ${ }^{3}$ In addition, $H$. pylori eradication therapy has been shown to be effective at preventing gastric cancer in several well-conducted clinical trials. ${ }^{4-8}$ Therefore, according to the Kyoto global consensus report, it is recommended that all infected patients be treated, irrespective of age or the severity of the gastric mucosal lesions, especially in regions with a high incidence of gastric cancer. $^{9-12}$

However, Uemura et al. ${ }^{13}$ reported that the rate of gastric cancer in patients with $H$. pylori infection was only $2.9 \%$ over a mean follow-up period of 7.8 years. Furthermore, according to data from previous trials, 125 patients would need to be treated with $H$. pylori eradication therapy to prevent one case of gastric cancer. ${ }^{14}$ However, $H$. pylori eradication cannot reduce the cancer risk to zero. ${ }^{15}$ Thus, no strategy to prevent gastric cancer has been established. Our next challenge will be the proper selection of target populations for screening endoscopies. In this review, we summarize potentially useful epidemiological, biological, and molecular findings to further optimize strategies for the early detection and risk stratification of gastric cancer (Table 1, Fig. 1). 
Table 1. Methodology for Risk Stratification and/or the Early Detection of Gastric Cancer

\begin{tabular}{|c|c|c|}
\hline Methods & Strength & Limitation \\
\hline Endoscopic findings & $\begin{array}{l}\text { - Essential for the diagnosis of cancer location } \\
\text { - Macroscopic diagnosis of the extent of metaplasia (Kimura } \\
\text { and Takemoto classification) is associated with the cancer } \\
\text { risk } \\
\text { - Improvement of image-enhancing endoscopy }\end{array}$ & $\begin{array}{l}\text { - Sometimes painful/stressful for some individuals } \\
\text { - Well-trained clinicians are necessary } \\
\text { - Risk of adverse events (perforation, etc.) }\end{array}$ \\
\hline Histological findings & $\begin{array}{l}\text { - Essential for the definitive diagnosis of dysplasia and cancer } \\
\text { - OLGA staging system is well associated with the cancer risk }\end{array}$ & $\begin{array}{l}\text { - Invasive } \\
\text { - Risk of adverse events (bleeding, etc.) } \\
\text { - Results of the analysis depend on the sampling point }\end{array}$ \\
\hline Tissue biomarkers & $\begin{array}{l}\text { - Molecules related to the metaplasia-dysplasia-adenocar- } \\
\text { cinoma sequence assist the histological diagnosis (TFF2, } \\
\text { CDX2, miR-124a-3p methylation, etc.) } \\
\text { CD44V9 pathway and MMPs could predict the cancer risk } \\
\text { independently from histological findings }\end{array}$ & $\begin{array}{l}\text { - Invasive } \\
\text { - Risk of adverse events (bleeding, etc.) } \\
\text { - Results of the analysis depend on the sampling point }\end{array}$ \\
\hline Gastric microbiota & $\begin{array}{l}\text { - Causal relationship between cancer development and the } \\
\text { presence of carcinogenic microbes is expected } \\
\text { Potentially less-invasive diagnosis by sampling of gastric } \\
\text { juice }\end{array}$ & - Limited evidences in human \\
\hline Serum pepsinogen & $\begin{array}{l}\text { - Good association with the severity of gastric mucosal atro- } \\
\text { phy in Helicobacter pylori-positive individuals } \\
\text { - Minimally invasive }\end{array}$ & $\begin{array}{l}\text { - No association with the severity of gastric mucosal at- } \\
\text { rophy after } H \text {. pylori eradication } \\
\text { - Confirmation of the present } H \text {. pylori infection is neces- } \\
\text { sary }\end{array}$ \\
\hline Plasma ghrelin & $\begin{array}{l}\text { - Expected association with the severity of gastric mucosal } \\
\text { atrophy irrespective of the presence of } H \text {. pylori } \\
\text { - Minimally invasive }\end{array}$ & - Limited evidences in human \\
\hline $\begin{array}{l}\text { Innovative blood-based } \\
\text { biomarkers (cell-free } \\
\text { DNA, cell-free RNA, } \\
\text { etc.) }\end{array}$ & $\begin{array}{l}\text { - Highly accurate early stage diagnosis is expected } \\
\text { - Potential organ specificity is expected for some biomarkers } \\
\text { - Minimally invasive }\end{array}$ & $\begin{array}{l}\text { - Unclear molecular mechanisms } \\
\text { - Further improvement of analytical methodology is nec- } \\
\text { essary } \\
\text { - Potentially expensive }\end{array}$ \\
\hline CEA, CA19-9 & $\begin{array}{l}\cdot \text { Low cost } \\
\text { - Minimally invasive }\end{array}$ & - Low sensitivity and specificity for early stage cancer \\
\hline
\end{tabular}

OLGA, Operative Link for Gastritis Assessment; TFF2, trefoil factor 2; CD44v9, CD44 variant 9; MMPs, matrix metallopeptidases; CEA, carcinoembryonic antigen; CA19-9, carbohydrate antigen 19-9.

\section{RISK STRATIFICATION BASED ON HISTOLOGY AND MORPHOLOGY}

Atrophic gastritis is the initial step in non-cardia gastric carcinogenesis. Gastric mucosal atrophy consists of both the absolute loss of resident glandular units and the transformation of native glands to intestinal metaplasia or spasmolytic polypeptide-expressing metaplasia (SPEM). Rugge et al. ${ }^{16,17}$ have established a gastritis staging system (stage 0 , I, II, III, and IV) based on histology called the Operative Link for Gastritis Assessment (OLGA) system. OLGA stage is determined by combining the atrophy scores in the corpus and antrum, and reflects the risk of progression to gastric cancer. The atrophy score is a four-tiered scale (0-3), based on the visual analogue scale of the updated Sydney system. ${ }^{18}$ OLGA staging also requires a five-point biopsy: two from the antral mucosa, one from the mucosa of the angularis incisura, and two from the oxyntic area. In a large European study in which patients were followed for 5 years after $H$. pylori eradication, neoplastic lesions only occurred in patients that had stage III or IV gastritis at the time of enrollment. ${ }^{19}$

In Japan, to avoid the risks of multiple gastric biopsies, the macroscopic extent of gastric mucosal atrophy is traditionally classified using the Kimura and Takemoto classification system, ${ }^{20}$ which correlates with the results of histological evaluation. ${ }^{21}$ Based on endoscopic findings, gastric mucosal atrophy is classified as the closed type (C-1 to C-3), which is characterized by borders of atrophy that do not exceed the cardia on the lesser curvature side of the gastric corpus, and the open-type (O-1 to O-3), which is characterized by borders of atrophy that exceed the cardia into the greater curvature side. ${ }^{20}$ Open-type atrophy is a significant risk factor for gastric cancer, although followup strategies based on the Kimura and Takemoto classification have not been established. ${ }^{22,23}$ Linked color imaging, a newly developed image-enhancing endoscopy technique, can detect map-like redness (a high risk feature) and regular arrangement of collecting venules (a low risk feature) more accurately than conventional white-color imaging. ${ }^{24}$ Thus, histological and endoscopic approaches are useful for identifying high risk groups. However, carcinogenesis is 


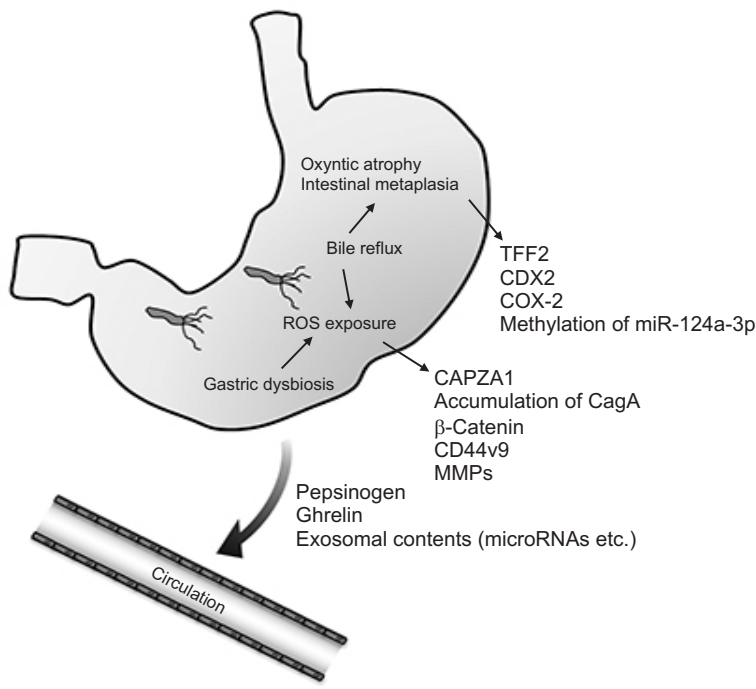

Fig. 1. Core etiologies of gastric carcinogenesis and potential biomarkers for risk stratification and early detection. Unhealthy intragastric conditions, such as Helicobacter pylori infection, dysbiosis, and bile reflux, induce the accumulation of reactive oxygen species (ROS) and gastric mucosal atrophy/intestinal metaplasia. Levels of several tissue biomarker molecules (as indicated) are altered during carcinogenesis. To achieve a minimally invasive means of evaluation, blood-based diagnostic strategies are needed.

TFF2, trefoil factor 2; COX, cyclooxygenase; CAPZA1, capping actin protein of muscle Z-line alpha subunit 1; CD44v9, CD44 variant 9; MMPs, matrix metallopeptidases.

observed frequently among histologically low risk patients. For more accurate risk stratification, a combination of histological evaluation and other markers is necessary.

\section{MOLECULAR DIAGNOSIS OF GASTRIC MUCOSAL ATROPHY AND INTESTINAL METAPLASIA}

Immunostaining of several protein markers in noncancer gastric tissues can assist diagnosis of gastric mucosal atrophy. For example, immunostaining for trefoil factor 2 (TFF2) assists histological assessment of SPEM. ${ }^{25,26}$ LIcadherin staining has good sensitivity and specificity for detecting intestinal metaplasia. ${ }^{27}$

In addition to $H$. pylori infection, the major etiological factor for the extension of atrophic mucosa is duodenogastric bile reflux. ${ }^{28}$ Dixon et al. ${ }^{29}$ reported that the independent risk factors for cardia intestinal metaplasia were increasing age, male sex, chronic inflammation, and significant bile reflux. Bile acids induce the production of reactive oxygen species (ROS), which cause DNA damage and activate nuclear factor- $\kappa \mathrm{B}$, resulting in production of inflammatory factors such as CDX2, epidermal growth factor receptor, interleukin (IL)-1 $\beta$, IL-8, and cyclooxygen- ase (COX)-2..$^{30-33}$

Epigenetic alterations, represented by aberrant DNA methylation, are deeply involved in carcinogenesis. Aberrant methylation accumulates during gastric mucosal atrophy and can contribute to cancer development. ${ }^{34,35}$ This suggests that the mucosal methylation status could be useful for the molecular diagnosis of the severity of gastric mucosal atrophy. ${ }^{36}$ In fact, the methylation of miR-124a$3 \mathrm{p}, E M X 1$, and NKX6-1 in biopsy samples taken from the lesser curvature $2 \mathrm{~cm}$ from the pyloric ring was significantly associated with the cumulative incidence of metachronous gastric cancers in patients after endoscopic resection of early gastric cancer. ${ }^{37}$

\section{STEM CELL MARKER CD44 VARIANT} 9-RELATED MOLECULES

CD44, a major adhesion molecule and receptor for hyaluronic acid, has been implicated in a variety of physiological processes in addition to cancer cell growth, invasion, and metastasis. ${ }^{38}$ Alternative splicing of CD44 mRNA produces a standard isoform of CD44 (CD44s) plus several variant isoforms. Among these, CD44 variant 9 (CD44v9) is the most unique phenotype that characterizes cancer stem cell-like properties. ${ }^{39}$ In fact, reciprocal silencing of total CD44 results in reduced tumor-initiating potential of gastric cancer cells, which can be rescued by expression of $\mathrm{CD} 44 \mathrm{v} 9$ but not by that of $\mathrm{CD} 44 \mathrm{~s} .{ }^{40} \mathrm{CD} 44 \mathrm{v} 9$ interacts with $\mathrm{xCT}$, a glutamate-cystine transporter, and to contribute to ROS defense by promoting the synthesis of the primary intracellular antioxidant glutathione, thereby promoting tumor growth and chemoresistance. ${ }^{41,42}$ CD44v9 expression is observed not only in cancer tissues, but also in gastric mucosal epithelium infected with $H$. pylori. ${ }^{43,44}$ We reported that $\mathrm{CD} 44 \mathrm{v} 9$-positive cells originate from capping actin protein of muscle Z-line alpha subunit 1 (CAPZA1)overexpressing cells in the gastric epithelium. ${ }^{45} \mathrm{CAPZA} 1$ overexpression enhanced the expression of $\beta$-catenin, which is a transcription factor for CD44, and ESRP1 (epithelial splicing regulatory protein 1 ), which increases alternative splicing of CD44 to generate CD44v9. ${ }^{45}$

On the other hand, $H$. pylori produces the oncogenic protein CagA and delivers it into the gastric epithelial cell cytoplasm via a type IV transporter. CagA induces cell proliferation and division by interacting with target molecules such as the cytoplasmic Src homology 2 domain of SHP-2 (Src homology 2 phosphatase). ${ }^{46}$ CagA is characterized by the presence of five repeating amino acid sequences (GluPro-Ile-Tyr-Ala), designated EPIYA motifs. Four different EPIYA motifs (EPIYA-A, EPIYA-B, EPIYA-C, and EPIYA- 
D) have been defined. Based on the EPIYA motifs, the CagA protein has been classified into Western and Eastern types. The Western type contains EPIYA-A and EPIYA$B$, followed by up to five repeated sequences of EPIYA-C, whereas the East Asian strain contains EPIYA-A, EPIYA$\mathrm{B}$, and EPIYA-D. ${ }^{47}$ The East Asian strain has been shown to be more virulent than the Western strain with respect to clinical outcomes. ${ }^{48}$

As a defense mechanism of host cells, CagA is degraded by autophagy irrespective of the type of EPIYA motif. ${ }^{49}$ However, in CAPZA1-overexpressing cells, autolysosome formation is inhibited and CagA escapes autophagic degradation. ${ }^{50}$ The accumulated CagA promotes CD44v9 expression by inducing the nuclear accumulation of $\beta$-catenin. ${ }^{45,49}$ Furthermore, ROS triggers CAPZA1 expression by increasing histone $\mathrm{H} 3$ acetylation of the CAPZA1 promoter. ${ }^{45}$ Furthermore, a CD44v9-xCT system-targeting intervention prevents development of preneoplastic lesions and cancer in mice. ${ }^{51}$ Thus, the ROS/CAPZA1/ $\mathrm{CagA} / \beta$-catenin/CD44v9/xCT axis could be a key pathway in gastric cancer development. In fact, we showed that $\mathrm{CD} 44 \mathrm{v} 9$ expression was a better predictor of gastric cancer recurrence after resection of early gastric cancer than the presence of open-type gastric mucosal atrophy. ${ }^{22}$

Although other variant isoforms are expressed in the gastric mucosa, the functions of each variant are unclear. ${ }^{52}$ CD44v6 acts as a co-receptor for the function of c-Met in response to $H$. pylori infection and CagA-induced epithelial proliferation. ${ }^{53}$

\section{MATRIX METALLOPEPTIDASES}

Studies of the interaction between gastric epithelium and immune responses reveal that matrix metallopeptidases (MMPs) play key roles. MMPs are a multimember family of zinc-containing endopeptidases with a wide substrate specificity; MMPs degrade extracellular matrix proteins during tissue morphogenesis and remodeling in wound healing. In addition, MMPs modify a multitude of nonmatrix substrates such as cytokines, chemokines, growth factors, and growth factor receptors, as well as cell-surface adhesion receptors. $^{54}$

H. pylori infection and translocation of CagA to gastric epithelial cells induces EPIYA phosphorylation-dependent up-regulation of MMP-1, MMP-3, MMP-7, MMP-9, and MMP-10, along with CD44. ${ }^{38,54-57}$ MMP-10-associated inflammation is characterized by influx of $\mathrm{CD} 8^{+} \mathrm{T}$ cells, whose migration is induced via the MMP-10-CXCL16 axis in gastric epithelial cells. ${ }^{58}$ The MMP-9-1562 SNP results in gender-specific differences in the risk of intestinal metapla- sia after $H$. pylori infection. ${ }^{59}$ By contrast, MMP-7 inhibits H. pylori-induced gastric injury and development of premalignant lesions via Th1- and Th17-mediated pathways, and by suppressing M1 macrophage polarization. ${ }^{60,61}$ Thus, altered expression of MMPs is associated with immune responses and carcinogenesis in the gastric epithelium, and it may serve as a tissue biomarker for cancer risk stratification and/or be a molecular target for cancer prevention.

\section{GASTRIC MICROBIOTA COMPOSITION}

Until recently, the acidic environment of the stomach was thought to prevent bacterial colonization since indigenous bacteria from the stomach had not been successfully isolated in culture. However, recent technological advances such as DNA sequencing of ribosomal RNA genes and phylogenetic analysis confirmed the existence of a diverse gastric microbiota in humans. The gastric microbiota is strongly influenced by $H$. pylori infection. ${ }^{62-64}$ Changes in the gastric environment such as changes in gastric acid secretion can drastically change the gastric microbiota. The overgrowth of pathobionts can promote inflammatory responses in the stomach, potentially leading to the development of gastric cancer.

Lofgren et al..$^{65}$ used human gastrin-overexpressing transgenic mice (INS-GAS mice), which develop gastric cancer upon $H$. pylori infection, to understand this effect. Under specific pathogen-free (SPF) conditions, H. pylori infection induced the onset of gastric cancer within 7 months of infection, whereas infection of germ-free INSGAS mice with $H$. pylori did not cause tumorigenesis. ${ }^{65}$ In addition, co-infection of germ-free INS-GAS mice with $H$. pylori and three other intestinal bacteria species (ASF356 Clostridium species, ASF361 Lactobacillus murinus, and ASF519 Bacteroides species) led to gastric neoplasia formation, similar to $H$. pylori infection under SPF conditions. ${ }^{66}$ These results suggest that gastric cancer onset is dependent on the presence of symbiotic bacteria that synergize with $H$. pylori infection.

According to analysis of human samples, the most common bacteria detected in individuals with $H$. pylori-associated gastritis are Helicobacter, Streptococcus, Prevotella, and Neisseria. ${ }^{67,68}$ These symbiotic bacteria mainly colonize the oral cavity and esophagus. However, in individuals with gastric cancer, the numbers of Helicobacter falls significantly, whereas Citrobacter, Clostridium, Lactobacillus, Achromobacter, and Rhodococcus are more abundant. ${ }^{67}$ These bacteria are mainly symbionts colonizing the lower gastrointestinal tract mucosa. Interestingly, abundantly detected bacteria in patients with gastric cancer have high 
nitric acid reductase and nitrous acid reductase activity. These bacteria effectively regenerate nitrite, the precursor of $\mathrm{N}$-nitroso compounds, from nitrate. ${ }^{67}$ Conjugated bile acids are a major source of nitrosamides in humans. Bile acids are normally present as cholic acid amides of glycine or taurine, and these amides are $N$-nitrosated by gastric bacteria. $\mathrm{N}$-nitrosoglycocholic acid and $\mathrm{N}$-nitrosotaurocholic acid are mutagenic and can contribute to the development of gastric cancer. ${ }^{69,70}$ Thus, the investigation of non- $H$. pylori components of the gastric microbiota will be of crucial importance for the risk stratification of gastric cancer.

\section{BLOOD-BASED TESTING FOR RISK STRATIFICATION}

Altered levels of serum pepsinogens (PGs), which are mainly produced by the chief cells of the fundic glands of the stomach, reflect the atrophic status of the gastric mucosa. ${ }^{71}$ While PG II is produced by both the antrum and the corpus mucosa, PG I is a marker of oxyntic mucosa status: any (metaplastic or non-metaplastic) loss of oxyntic glands results in lower PG I levels and a lower PG I/II ratio. The combination of the serum PG I level and the PG I/II ratio is a good predictor of gastric cancer occurrence in $H$. pylori-infected populations. ${ }^{72-74}$ In fact, a 20 -year prospective cohort study of a Japanese population revealed that the combination of serum H. pylori antibody and PG levels is a significant predictor of gastric cancer risk. ${ }^{75}$ When participants were categorized into four groups (group A [H. pylori-, PG-], group B [H. pylori+, PG-], group C [H. pylori+, $\mathrm{PG}+]$, and group $\mathrm{D}[\mathrm{H}$. pylori-, $\mathrm{PG}+])$, the risk of gastric cancer in group B had a hazard ratio of $4.08(95 \%$ confidence interval $[\mathrm{CI}], 1.62$ to 10.28 ), whereas that in groups C/D was 11.1 (95\% CI, 4.45 to 27.46) when group A was used as the reference group. ${ }^{75}$ However, PG I and II decrease, and the PG I/II ratio increases, after successful $H$. pylori eradication, irrespective of any improvement in mucosal atrophy. ${ }^{76,77}$ Therefore, the serum PG level is a useful tool for gastric cancer risk stratification among individuals with $H$. pylori infection. For individuals after eradication, other noninvasive biomarkers of atrophic status are needed for risk stratification.

Ghrelin is a 28-amino-acid appetite-stimulating peptide hormone secreted by the A-like cells of the oxyntic glands of the stomach. Under conditions of gastric mucosal atrophy, as the number of A-like cells decreases, the plasma ghrelin concentration also decreases. ${ }^{78}$ In fact, the plasma levels of total and active ghrelin correlate with the serum PG I level, as well as the serum PG I/II ratio, and decrease as the extent of gastric mucosal atrophy increases. ${ }^{79,80}$ More studies are needed on the reliability of plasma ghrelin levels for gastric cancer risk stratification.

TFF2 (produced during SPEM) and TFF3 (produced during intestinal metaplasia) can be detected in serum. Kuo et al. ${ }^{81}$ investigated whether serum levels of TFF2 and TFF3 predict cancer-associated histology. Neither IM nor SPEM were associated with serum TFF2 or TFF3. Serum TFF2 levels were higher in participants with corpus gastritis who also had advanced SPEM. For participants without corpus gastritis, elevated serum TFF2 levels correlate with higher $H$. pylori density and more severe gastritis in the antrum. These results suggest that serum levels of TFF2 are associated with the extent of SPEM, as well as with the risk of gastric cancer.

\section{BLOOD-BASED TESTING FOR EARLY DETECTION}

Conventional serum tumor biomarkers such as carcinoembryonic antigen and carbohydrate antigen (CA) 19-9 are unsuitable for early gastric cancer detection due to their insufficient specificity and sensitivity. Compared with these, serum TFF3 is a good biomarker for predicting the presence of gastric cancer. ${ }^{82}$ The area under the receiver operating characteristics curve (AUROC) of TFF3 for predicting gastric cancer was 0.65 to $0.81 .^{82-84}$

Furthermore, recent liquid biopsy technologies could provide us with more accurate diagnostic tools based on the analysis of cell-free DNA (cfDNA), microRNA (miRNA), or extracellular vesicles. ${ }^{85}$ Circulating cfDNA is cell-free extracellular DNA originating from normal and cancerous cells in the blood. The fraction of cfDNA that derives from primary tumors, metastases, or circulating tumor cells is called circulating tumor DNA (ctDNA). A recent meta-analysis showed that detection of ctDNA resulted in increased gastric cancer diagnosis specificity over conventional protein biomarkers, but there was no increase in sensitivity. ${ }^{86}$

Dysregulated miRNAs can contribute to cancer initiation and development. miRNAs are short regulatory RNA molecules of 17 to 25 nucleotides in length. They modulate target gene expression at the post-translational level by guiding the RNA-induced silencing complex to miRNA target sites in the $3^{\prime}$ untranslated region of mRNAs, leading to mRNA degradation or the inhibition of translation. Expression profiling has shown distinctive miRNA signatures in different cancers, including gastric cancer. ${ }^{87}$ miRNAs are secreted by cells mainly via exosomes, and are detectable in the circulation. ${ }^{88,89}$ Circulating miRNA profiles are associ- 
ated with various disease conditions and can be good biomarkers. ${ }^{85}$ Previous reports have shown that miRNA profiles can accurately discriminate between patients with and without gastric cancer. For example, Shin et al. ${ }^{90}$ showed that the combination of plasma miR-627, miR-629, and miR-652 resulted in the highest AUROC with a sensitivity of $86.7 \%$ and a specificity of $85.5 \%$. Liu et al..$^{91}$ reported that serum levels of miR-1, miR-20a, miR-27a, miR-34, and miR-423-5p achieved an AUROC of 0.879. Zhou et al. ${ }^{92}$ reported that plasma levels of miR-185, miR-20a, miR-210, miR-25, and miR-92b resulted in an AUROC of 0.87. Hou et $a{ }^{93}$ reported that serum miRNA-206 not only served as a novel diagnostic biomarker (AUROC, 0.89), but also predicted cancer recurrence and patient prognosis. Zhu et al. ${ }^{94}$ reported that the combination of plasma miR-16, miR-25, miR-92a, miR-451, and miR-486-5p acted as a potential biomarker for detecting non-cardia gastric cancer, with an AUROC of 0.812. A recent review summarizes other related reports. ${ }^{95}$ Thus, patients with gastric cancer seem to have distinct circulating miRNA profiles. However, the specific miRNAs that were identified in these studies varied. The protocols that are used for RNA extraction and miRNA quantification can significantly affect the results. ${ }^{96}$ Worldwide standardization of the methods for evaluating circulating miRNAs will be essential for the clinical application of the miRNA profile.

Other cell-free RNAs, such as LMX1A mRNA,${ }^{97}$ long non-coding RNAs (lncRNAs), ${ }^{98}$ and circular RNAs (circRNAs) ${ }^{99}$ are also potential biomarkers for cancer detection. Tumor-educated platelet RNA signatures could be useful for detecting early stage cancer. ${ }^{100}$ Thus, knowledge of various innovative blood-based cancer detection methods is rapidly accumulating, which could lead to marked changes in future clinical practice.

\section{CONCLUSIONS}

Given recent advances in DNA sequencing technology, many next generation biomarkers are being utilized. Traditionally, clinicians have tried to predict the risk of gastric carcinogenesis based on the severity of gastric mucosal atrophy. To achieve further risk stratification, further investigation of ROS-related alterations in the gastric mucosa and gastric pathobionts are warranted. Pathogenic gastric microbial species could be a good biomarker for the risk of carcinogenesis as well as a potential source of therapeutic targets. Establishment of less invasive blood-based examinations is expected and desirable. Ultimately, surveillance of gastric cancer should be performed via blood tests. To determine the appropriate interval for blood-based sur- veillance, risk stratification based on blood tests should be performed. Only individuals with suspected gastric cancer will undergo endoscopy for definitive diagnosis and to determine the therapeutic strategy. Every promising biomarker should to be verified strictly and prospectively, although it will take many years to obtain evidence that these markers reduce mortality. We must keep on addressing the issue and construct an ideal screening strategy, based on several biomarkers, for the next generation.

\section{CONFLICTS OF INTEREST}

No potential conflict of interest relevant to this article was reported.

\section{ACKNOWLEDGEMENTS}

This work was supported by a Grant-in-Aid for Scientific Research C (17K09471, to J.M.) from the Japan Society for the Promotion of Science (JSPS).

\section{AUTHOR CONTRIBUTIONS}

Writing - original draft: J.M., H.T. Writing - review and editing: H.S. Approval of final manuscript: all authors.

\section{ORICD}

Juntaro Matsuzaki https://orcid.org/0000-0002-3204-5049 Hitoshi Tsugawa https://orcid.org/0000-0002-4344-4475 Hidekazu Suzuki https://orcid.org/0000-0002-8994-6163

\section{REFERENCES}

1. Ferlay J, Colombet M, Soerjomataram I, et al. Estimating the global cancer incidence and mortality in 2018: GLOBOCAN sources and methods. Int J Cancer 2019;144:1941-1953.

2. Helicobacter and Cancer Collaborative Group. Gastric cancer and Helicobacter pylori: a combined analysis of 12 case control studies nested within prospective cohorts. Gut 2001;49:347-353.

3. Zhang X, Li M, Chen S, et al. Endoscopic screening in Asian countries is associated with reduced gastric cancer mortality: a meta-analysis and systematic review. Gastroenterology 2018;155:347-354.

4. Suzuki H, Matsuzaki J. Gastric cancer: evidence boosts He- 
licobacter pylori eradication. Nat Rev Gastroenterol Hepatol 2018;15:458-460.

5. Choi IJ, Kook MC, Kim YI, et al. Helicobacter pylori therapy for the prevention of metachronous gastric cancer. N Engl J Med 2018;378:1085-1095.

6. Fukase K, Kato M, Kikuchi S, et al. Effect of eradication of Helicobacter pylori on incidence of metachronous gastric carcinoma after endoscopic resection of early gastric cancer: an open-label, randomised controlled trial. Lancet 2008;372:392-397.

7. Ma JL, Zhang L, Brown LM, et al. Fifteen-year effects of Helicobacter pylori, garlic, and vitamin treatments on gastric cancer incidence and mortality. J Natl Cancer Inst 2012;104:488-492.

8. Mera RM, Bravo LE, Camargo MC, et al. Dynamics of Helicobacter pylori infection as a determinant of progression of gastric precancerous lesions: 16-year follow-up of an eradication trial. Gut 2018;67:1239-1246.

9. Sugano K, Tack J, Kuipers EJ, et al. Kyoto global consensus report on Helicobacter pylori gastritis. Gut 2015;64:13531367.

10. Suzuki H, Mori H. Helicobacter pylori: Helicobacter pylori gastritis: a novel distinct disease entity. Nat Rev Gastroenterol Hepatol 2015;12:556-557.

11. Malfertheiner P, Megraud F, O'Morain CA, et al. Management of Helicobacter pylori infection-the Maastricht V/Florence Consensus Report. Gut 2017;66:6-30.

12. Sugano K. Effect of Helicobacter pylori eradication on the incidence of gastric cancer: a systematic review and metaanalysis. Gastric Cancer 2019;22:435-445.

13. Uemura N, Okamoto S, Yamamoto S, et al. Helicobacter pylori infection and the development of gastric cancer. N Engl J Med 2001;345:784-789.

14. Malfertheiner P. Helicobacter pylori treatment for gastric cancer prevention. N Engl J Med 2018;378:1154-1156.

15. Tan MC, Graham DY. Gastric cancer risk stratification and surveillance after Helicobacter pylori eradication: 2020. Gastrointest Endosc 2019;90:457-460.

16. Rugge M, de Boni M, Pennelli G, et al. Gastritis OLGA-staging and gastric cancer risk: a twelve-year clinico-pathological follow-up study. Aliment Pharmacol Ther 2010;31:11041111.

17. Rugge M, Meggio A, Pennelli G, et al. Gastritis staging in clinical practice: the OLGA staging system. Gut 2007;56:631636.

18. Dixon MF, Genta RM, Yardley JH, Correa P. Classification and grading of gastritis: the updated Sydney System. International Workshop on the Histopathology of Gastritis, Houston 1994. Am J Surg Pathol 1996;20:1161-1181.

19. Rugge M, Meggio A, Pravadelli C, et al. Gastritis staging in the endoscopic follow-up for the secondary prevention of gastric cancer: a 5-year prospective study of 1755 patients. Gut 2019;68:11-17.

20. Kimura K, Takemoto T. An endoscopic recognition of the atrophic border and its significance in chronic gastritis. Endoscopy 1969;1:87-97.

21. Ito S, Azuma T, Murakita H, et al. Profile of Helicobacter pylori cytotoxin derived from two areas of Japan with different prevalence of atrophic gastritis. Gut 1996;39:800-806.

22. Hirata K, Suzuki H, Imaeda H, et al. CD44 variant 9 expression in primary early gastric cancer as a predictive marker for recurrence. Br J Cancer 2013;109:379-386.

23. Masuyama H, Yoshitake N, Sasai T, et al. Relationship between the degree of endoscopic atrophy of the gastric mucosa and carcinogenic risk. Digestion 2015;91:30-36.

24. Majima A, Dohi O, Takayama S, et al. Linked color imaging identifies important risk factors associated with gastric cancer after successful eradication of Helicobacter pylori. Gastrointest Endosc 2019;90:763-769.

25. Rugge M, Sugano K, Scarpignato C, Sacchi D, Oblitas WJ, Naccarato AG. Gastric cancer prevention targeted on risk assessment: Gastritis OLGA staging. Helicobacter 2019;24:e12571.

26. Minegishi Y, Suzuki H, Arakawa M, et al. Reduced Shh expression in TFF2-overexpressing lesions of the gastric fundus under hypochlorhydric conditions. J Pathol 2007;213:161169.

27. Grötzinger C, Kneifel J, Patschan D, et al. LI-cadherin: a marker of gastric metaplasia and neoplasia. Gut 2001;49:7381.

28. Matsuzaki J, Suzuki H, Tsugawa $\mathrm{H}$, et al. Bile acids increase levels of microRNAs 221 and 222, leading to degradation of CDX2 during esophageal carcinogenesis. Gastroenterology 2013;145:1300-1311.

29. Dixon MF, Mapstone NP, Neville PM, Moayyedi P, Axon AT. Bile reflux gastritis and intestinal metaplasia at the cardia. Gut 2002;51:351-355.

30. Huo X, Juergens S, Zhang X, et al. Deoxycholic acid causes DNA damage while inducing apoptotic resistance through NF- $\kappa B$ activation in benign Barrett's epithelial cells. Am J Physiol Gastrointest Liver Physiol 2011;301:G278-G286.

31. Jenkins GJ, D’Souza FR, Suzen SH, et al. Deoxycholic acid at neutral and acid $\mathrm{pH}$, is genotoxic to oesophageal cells through the induction of ROS: the potential role of anti-oxidants in Barrett's oesophagus. Carcinogenesis 2007;28:136142.

32. McAdam E, Haboubi HN, Griffiths AP, et al. Reflux composition influences the level of NF- $\mathrm{BB}$ activation and upstream kinase preference in oesophageal adenocarcinoma cells. Int J Cancer 2015;136:527-535.

33. Cronin J, McAdam E, Danikas A, et al. Epidermal growth factor receptor (EGFR) is overexpressed in high-grade 
dysplasia and adenocarcinoma of the esophagus and may represent a biomarker of histological progression in Barrett's esophagus (BE). Am J Gastroenterol 2011;106:46-56.

34. Saito Y, Suzuki H, Taya T, et al. Development of a novel microRNA promoter microarray for ChIP-on-chip assay to identify epigenetically regulated microRNAs. Biochem Biophys Res Commun 2012;426:33-37.

35. Saito Y, Suzuki H, Tsugawa H, et al. Chromatin remodeling at Alu repeats by epigenetic treatment activates silenced microRNA-512-5p with downregulation of Mcl-1 in human gastric cancer cells. Oncogene 2009;28:2738-2744.

36. Suzuki R, Yamamoto E, Nojima M, et al. Aberrant methylation of microRNA-34b/c is a predictive marker of metachronous gastric cancer risk. J Gastroenterol 2014;49:1135-1144.

37. Asada K, Nakajima T, Shimazu T, et al. Demonstration of the usefulness of epigenetic cancer risk prediction by a multicentre prospective cohort study. Gut 2015;64:388-396.

38. Garcia M, Chomel JC, Mustapha P, et al. In vitro culture and phenotypic and molecular characterization of gastric stem cells from human stomach. Helicobacter 2017;22:12351.

39. Zavros Y. Initiation and maintenance of gastric cancer: a focus on CD44 variant isoforms and cancer stem cells. Cell Mol Gastroenterol Hepatol 2017;4:55-63.

40. Lau WM, Teng E, Chong HS, et al. CD44v8-10 is a cancerspecific marker for gastric cancer stem cells. Cancer Res 2014;74:2630-2641.

41. Ishimoto T, Nagano O, Yae T, et al. CD44 variant regulates redox status in cancer cells by stabilizing the $\mathrm{xCT}$ subunit of system $\mathrm{xc}(-)$ and thereby promotes tumor growth. Cancer Cell 2011;19:387-400.

42. Miyoshi S, Tsugawa H, Matsuzaki J, et al. Inhibiting xCT improves 5-fluorouracil resistance of gastric cancer induced by CD44 variant 9 expression. Anticancer Res 2018;38:61636170.

43. Ishimoto $\mathrm{T}$, Izumi $\mathrm{D}$, Watanabe $\mathrm{M}$, et al. Chronic inflammation with Helicobacter pylori infection is implicated in CD44 overexpression through miR-328 suppression in the gastric mucosa. J Gastroenterol 2015;50:751-757.

44. Bertaux-Skeirik N, Wunderlich M, Teal E, et al. CD44 variant isoform 9 emerges in response to injury and contributes to the regeneration of the gastric epithelium. J Pathol 2017;242:463-475.

45. Tsugawa H, Kato C, Mori H, et al. Cancer stem-cell marker CD44v9-positive cells arise from Helicobacter pylori-infected CAPZA1-overexpressing cells. Cell Mol Gastroenterol Hepatol 2019;8:319-334.

46. Higashi H, Tsutsumi R, Muto S, et al. SHP-2 tyrosine phosphatase as an intracellular target of Helicobacter pylori CagA protein. Science 2002;295:683-686.

47. Nguyen LT, Uchida T, Murakami K, Fujioka T, Moriyama $\mathrm{M}$. Helicobacter pylori virulence and the diversity of gastric cancer in Asia. J Med Microbiol 2008;57(Pt 12):1445-1453.

48. Azuma T, Yamakawa A, Yamazaki S, et al. Distinct diversity of the cag pathogenicity island among Helicobacter pylori strains in Japan. J Clin Microbiol 2004;42:2508-2517.

49. Tsugawa H, Suzuki H, Saya H, et al. Reactive oxygen speciesinduced autophagic degradation of Helicobacter pylori CagA is specifically suppressed in cancer stem-like cells. Cell Host Microbe 2012;12:764-777.

50. Tsugawa $\mathrm{H}$, Mori $\mathrm{H}$, Matsuzaki J, et al. CAPZA1 determines the risk of gastric carcinogenesis by inhibiting Helicobacter pylori CagA-degraded autophagy. Autophagy 2019;15:242258.

51. Wada T, Ishimoto T, Seishima R, et al. Functional role of CD44v-xCT system in the development of spasmolytic polypeptide-expressing metaplasia. Cancer Sci 2013;104:13231329.

52. Heider KH, Dämmrich J, Skroch-Angel P, et al. Differential expression of CD44 splice variants in intestinal- and diffusetype human gastric carcinomas and normal gastric mucosa. Cancer Res 1993;53:4197-4203.

53. Bertaux-Skeirik N, Feng R, Schumacher MA, et al. CD44 plays a functional role in Helicobacter pylori-induced epithelial cell proliferation. PLoS Pathog 2015;11:e1004663.

54. Sougleri IS, Papadakos KS, Zadik MP, Mavri-Vavagianni M, Mentis AF, Sgouras DN. Helicobacter pylori CagA protein induces factors involved in the epithelial to mesenchymal transition (EMT) in infected gastric epithelial cells in an EPIYA- phosphorylation-dependent manner. FEBS J 2016;283:206-220.

55. Costa AM, Ferreira RM, Pinto-Ribeiro I, et al. Helicobacter pylori activates matrix metalloproteinase 10 in gastric epithelial cells via EGFR and ERK-mediated pathways. J Infect Dis 2016;213:1767-1776.

56. Nam YH, Ryu E, Lee D, Shim HJ, Lee YC, Lee ST. CagA phosphorylation-dependent MMP-9 expression in gastric epithelial cells. Helicobacter 2011;16:276-283.

57. Yin Y, Grabowska AM, Clarke PA, et al. Helicobacter pylori potentiates epithelial:mesenchymal transition in gastric cancer: links to soluble HB-EGF, gastrin and matrix metalloproteinase-7. Gut 2010;59:1037-1045.

58. Lv YP, Cheng P, Zhang JY, et al. Helicobacter pylori-induced matrix metallopeptidase-10 promotes gastric bacterial colonization and gastritis. Sci Adv 2019;5:eaau6547.

59. Hung KH, Hung HW, Yang HB, Lu CC, Wu JJ, Sheu BS. Host single nucleotide polymorphisms of MMP-9 -1562/TIMP1372 have gender differences in the risk of gastric intestinal metaplasia after Helicobacter pylori infection. Helicobacter 2009;14:580-587.

60. Krakowiak MS, Noto JM, Piazuelo MB, et al. Matrix metalloproteinase 7 restrains Helicobacter pylori-induced gastric inflammation and premalignant lesions in the stomach by 
altering macrophage polarization. Oncogene 2015;34:18651871.

61. Ogden SR, Noto JM, Allen SS, et al. Matrix metalloproteinase-7 and premalignant host responses in Helicobacter pylori-infected mice. Cancer Res 2010;70:30-35.

62. Maldonado-Contreras A, Goldfarb KC, Godoy-Vitorino F, et al. Structure of the human gastric bacterial community in relation to Helicobacter pylori status. ISME J 2011;5:574579.

63. Jo HJ, Kim J, Kim N, et al. Analysis of gastric microbiota by pyrosequencing: minor role of bacteria other than Helicobacter pylori in the gastric carcinogenesis. Helicobacter 2016;21:364-374.

64. Schulz C, Schütte K, Koch N, et al. The active bacterial assemblages of the upper GI tract in individuals with and without Helicobacter infection. Gut 2018;67:216-225.

65. Lofgren JL, Whary MT, Ge Z, et al. Lack of commensal flora in Helicobacter pylori-infected INS-GAS mice reduces gastritis and delays intraepithelial neoplasia. Gastroenterology 2011;140:210-220.

66. Lertpiriyapong K, Whary MT, Muthupalani S, et al. Gastric colonisation with a restricted commensal microbiota replicates the promotion of neoplastic lesions by diverse intestinal microbiota in the Helicobacter pylori INS-GAS mouse model of gastric carcinogenesis. Gut 2014;63:54-63.

67. Ferreira RM, Pereira-Marques J, Pinto-Ribeiro I, et al. Gastric microbial community profiling reveals a dysbiotic cancer-associated microbiota. Gut 2018;67:226-236.

68. Yang I, Woltemate S, Piazuelo MB, et al. Different gastric microbiota compositions in two human populations with high and low gastric cancer risk in Colombia. Sci Rep 2016;6:18594.

69. Mukaisho K, Nakayama T, Hagiwara T, Hattori T, Sugihara $\mathrm{H}$. Two distinct etiologies of gastric cardia adenocarcinoma: interactions among $\mathrm{pH}$, Helicobacter pylori, and bile acids. Front Microbiol 2015;6:412.

70. Suo M, Mukaisho K, Shimomura A, Sugihara H, Hattori T. Thioproline prevents carcinogenesis in the remnant stomach induced by duodenal reflux. Cancer Lett 2006;237:256-262.

71. Samloff IM, Varis K, Ihamaki T, Siurala M, Rotter JI. Relationships among serum pepsinogen I, serum pepsinogen II, and gastric mucosal histology: a study in relatives of patients with pernicious anemia. Gastroenterology 1982;83(1 Pt 2):204-209.

72. Song M, Camargo MC, Weinstein SJ, et al. Serum pepsinogen 1 and anti-Helicobacter pylori IgG antibodies as predictors of gastric cancer risk in Finnish males. Aliment Pharmacol Ther 2018;47:494-503.

73. Oishi Y, Kiyohara Y, Kubo M, et al. The serum pepsinogen test as a predictor of gastric cancer: the Hisayama study. Am J Epidemiol 2006;163:629-637.
74. Ren JS, Kamangar F, Qiao YL, et al. Serum pepsinogens and risk of gastric and oesophageal cancers in the General Population Nutrition Intervention Trial cohort. Gut 2009;58:636642.

75. Ikeda F, Shikata K, Hata J, et al. Combination of Helicobacter pylori antibody and serum pepsinogen as a good predictive tool of gastric cancer incidence: 20 -year prospective data from the Hisayama study. J Epidemiol 2016;26:629-636.

76. Leja M, Lapina S, Polaka I, et al. Pepsinogen testing for evaluation of the success of Helicobacter pylori eradication at 4 weeks after completion of therapy. Medicina (Kaunas) 2014;50:8-13.

77. Hirata K, Suzuki H, Matsuzaki J, et al. Improvement of reflux symptom related quality of life after Helicobacter pylori eradication therapy. J Clin Biochem Nutr 2013;52:172-178.

78. Isomoto $\mathrm{H}$, Ueno $\mathrm{H}$, Nishi $\mathrm{Y}$, et al. Circulating ghrelin levels in patients with various upper gastrointestinal diseases. Dig Dis Sci 2005;50:833-838.

79. Suzuki H, Masaoka T, Hosoda H, et al. Plasma ghrelin concentration correlates with the levels of serum pepsinogen I and pepsinogen I/II ratio: a possible novel and noninvasive marker for gastric atrophy. Hepatogastroenterology 2004;51:1249-1254.

80. Kawashima J, Ohno S, Sakurada T, et al. Circulating acylated ghrelin level decreases in accordance with the extent of atrophic gastritis. J Gastroenterol 2009;44:1046-1054.

81. Kuo HY, Chang WL, Yeh YC, et al. Serum level of trefoil factor 2 can predict the extent of gastric spasmolytic polypeptide-expressing metaplasia in the $\mathrm{H}$. pylori-infected gastric cancer relatives. Helicobacter 2017;22:12320.

82. Kaise M, Miwa J, Tashiro J, et al. The combination of serum trefoil factor 3 and pepsinogen testing is a valid nonendoscopic biomarker for predicting the presence of gastric cancer: a new marker for gastric cancer risk. J Gastroenterol 2011;46:736-745.

83. Lee HS, Jeon SW, Nomura S, et al. Screening biomarker as an alternative to endoscopy for the detection of early gastric cancer: the combination of serum trefoil factor family 3 and pepsinogen. Gastroenterol Res Pract 2018;2018:1024074.

84. Huang Z, Zhang X, Lu H, et al. Serum trefoil factor 3 is a promising non-invasive biomarker for gastric cancer screening: a monocentric cohort study in China. BMC Gastroenterol 2014;14:74.

85. Matsuzaki J, Ochiya T. Circulating microRNAs and extracellular vesicles as potential cancer biomarkers: a systematic review. Int J Clin Oncol 2017;22:413-420.

86. Gao Y, Zhang K, Xi H, et al. Diagnostic and prognostic value of circulating tumor DNA in gastric cancer: a meta-analysis. Oncotarget 2017;8:6330-6340.

87. Rosenfeld N, Aharonov R, Meiri E, et al. MicroRNAs accurately identify cancer tissue origin. Nat Biotechnol 
2008;26:462-469.

88. Kosaka N, Iguchi H, Yoshioka Y, Takeshita F, Matsuki Y, Ochiya T. Secretory mechanisms and intercellular transfer of microRNAs in living cells. J Biol Chem 2010;285:1744217452.

89. Valadi H, Ekström K, Bossios A, Sjöstrand M, Lee JJ, Lötvall JO. Exosome-mediated transfer of mRNAs and microRNAs is a novel mechanism of genetic exchange between cells. Nat Cell Biol 2007;9:654-659.

90. Shin VY, Ng EK, Chan VW, Kwong A, Chu KM. A threemiRNA signature as promising non-invasive diagnostic marker for gastric cancer. Mol Cancer 2015;14:202.

91. Liu R, Zhang C, Hu Z, et al. A five-microRNA signature identified from genome-wide serum microRNA expression profiling serves as a fingerprint for gastric cancer diagnosis. Eur J Cancer 2011;47:784-791.

92. Zhou X, Zhu W, Li H, et al. Diagnostic value of a plasma microRNA signature in gastric cancer: a microRNA expression analysis. Sci Rep 2015;5:11251.

93. Hou CG, Luo XY, Li G. Diagnostic and prognostic value of serum microRNA-206 in patients with gastric cancer. Cell Physiol Biochem 2016;39:1512-1520.

94. Zhu C, Ren C, Han J, et al. A five-microRNA panel in plasma was identified as potential biomarker for early detection of gastric cancer. Br J Cancer 2014;110:2291-2299.

95. Link A, Kupcinskas J. MicroRNAs as non-invasive diagnostic biomarkers for gastric cancer: current insights and future perspectives. World J Gastroenterol 2018;24:3313-3329.

96. Kloten V, Neumann MHD, Di Pasquale F, et al. Multicenter evaluation of circulating plasma microRNA extraction technologies for the development of clinically feasible reverse transcription quantitative PCR and next-generation sequencing analytical work flows. Clin Chem 2019;65:11321140.

97. Li D, Li C. The diagnostic performance of serum LIM homeobox transcription factor 1 alpha in patients with gastric cancer. Medicine (Baltimore) 2019;98:e15783.

98. Zhou X, Yin C, Dang Y, Ye F, Zhang G. Identification of the long non-coding RNA H19 in plasma as a novel biomarker for diagnosis of gastric cancer. Sci Rep 2015;5:11516.

99. Tan H, Gan L, Fan X, Liu L, Liu S. Diagnostic value of circular RNAs as effective biomarkers for cancer: a systematic review and meta-analysis. Onco Targets Ther 2019;12:26232633.

100. Best MG, Wesseling P, Wurdinger T. Tumor-educated platelets as a noninvasive biomarker source for cancer detection and progression monitoring. Cancer Res 2018;78:3407-3412. 